\title{
Pengaruh Kompetensi Sumber Daya Manusia Dan Kemampuan Pemanfaatan Teknologi Terhadap Kinerja Aparatur Desa Pada Kantor Kepala Desa Di Kabupaten Gunungkidul, Yogyakarta
}

\author{
${ }^{1}$ Nurjaya, ${ }^{2}$ Azhar Affandi, ${ }^{3}$ Dodi Ilham, ${ }^{4}$ Jasmani, ${ }^{5}$ Denok Sunarsi \\ ${ }^{1}$ Universitas Suryakancana, Cianjur, Jawa Barat, Indonesia \\ ${ }^{2}$ Universitas Pasundan, Bandung, Jawa Barat, Indonesia \\ ${ }^{3}$ IAIN Palopo, Sulawesi Selatan, Indonesia \\ ${ }^{4.5}$ Universitas Pamulang, Tangerang Selatan, Banten, Indonesia \\ Email: $\underline{{ }^{1} \text { nurjaya@unsur.ac.id }}$
}

(Diterima: April 2021; Direvisi: April 2021; Dipublikasikan: Mei 2021)

\begin{abstract}
ABSTRAK
Penelitian ini bertujuan untuk mengetahui pengaruh Kompetensi Sumber Daya Manusia dan Kemampuan Pemanfaatan Teknologi terhadap Kinerja Aparatur Desa Pada Kantor Kepala Desa di Kabupaten Gunungkidul, Yogyakarta. Metode yang digunakan adalah explanatory research dengan teknik analisis menggunakan analisis statistik dengan pengujian regresi, korelasi, determinasi dan uji hipotesis. Hasil penelitian ini Kompetensi Sumber Daya Manusia berpengaruh signifikan terhadap Kinerja Aparatur Desa sebesar 41,5\%, uji hipotesis diperoleh $\mathrm{t}$ hitung $>\mathrm{t}$ tabel atau $(10,045>1,977)$. Kemampuan Pemanfaatan Teknologi berpengaruh signifikan terhadap Kinerja Aparatur Desa sebesar 42,7\%, uji hipotesis diperoleh t hitung > t tabel atau $(10,285>1,977)$. Kompetensi Sumber Daya Manusia dan Kemampuan Pemanfaatan Teknologi secara simultan berpengaruh signifikan terhadap Kinerja Aparatur Desa dengan persamaan regresi $\mathrm{Y}=6,025+0,391 \mathrm{X} 1+$ $0,461 \mathrm{X} 2$. Kontribusi pengaruh sebesar $57,3 \%$, uji hipotesis diperoleh $\mathrm{F}$ hitung $>\mathrm{F}$ tabel atau $(94,626>2,670)$.
\end{abstract}

Kata Kunci: Kompetensi Sumber Daya Manusia, Kemampuan Pemanfaatan Teknologi, Kinerja Aparatur Desa. 


\section{PENDAHULUAN}

Pengelolaan

manajemen

sumber daya manusia memiliki peran dalam pencapaian tujuan suatu lembaga, jika memliki aparatur yang memiliki kompetensi yang baik. Tujuan dari manajemen sumber daya manusia adalah untuk menciptakan sumber daya yang berkualitas, sehingga mampu mewujudkan layanan kepada masyarakat secara optimal.

Manajemen sumber daya manusia sebagai aset penting bagi lembaga perlu dipelihara dengan baik. Manusia berperan secara dinamis dalam kegiatan lembaga untuk mewuwujudkan tercapainya tujuan lembaga. Manajemen sumber daya manusia harus dapat menunjang tujuan lembaga dilingkungan perusahaan maupun lingkungan pemerintahan. Tujuan utama dari manajemen sumber daya manusia adalah menyiapkan dan mewujudkan sumber daya manusia yang berkualitas, kompetensi sumber daya manusia dianggap memenuhi kriteria jika sumber daya manusia ini dapat mewujudkan tujuan lembaga dengan memberikan pelayanan yang baik dan berkualitas Nawawi (2011).

Sumber daya manusia yang berkualitas dapat dilihat dari latar belakang pendidikan, pelatihan yang pernah diikuti, keterampilan yang dinyatakan dalam pelaksanaan tugas dan deskripsi jabatan. Kompetensi berhubungan dengan kemampuan yang harus dimiliki setiap individu agar dapat melakukan pekerjaannya dengan baik. Kompetensi merupakan kemampuan seseorang maka kualitas ini merupakan perpaduan antara keahlian (Skill) dan pengetahuan (knowledge) kemampuan (ability) untuk melaksanakan pekerjaan menjadi karakterisik individu untuk mencapai kinerja secara maksimal.

Desa memiliki wewenang dalam penyelenggaraan pemerintahan, pelaksanaan pembangunan, pembinaan kemasyarakatan, dan pemberdayaan masyarakat desa (Republik Indonesia, 2014). Desa dalam mengelola sumber-sumber pendapatan dan penggunaan dana desa perlu dilakukan dengan dengan baik.

Daerah Istimewa Yogyakarta memiliki 5 (lima) Kabupaten/Kota yang cukup luas, salah satunya adalah Kabupaten Gunungkidul yang terletak di sebelah selatan kota Yogyakarta. Kabupaten Gunungkidul adalah salah satu kabupaten yang ada di Propinsi Daerah Istimewa Yogyakarta, dengan Ibukotanya Wonosari. Luas wilayah Kabupaten Gunungkidul 1.485,36 km2 atau sekitar 46,63 \% dari luas wilayah Propinsi Daerah Istimewa YogyAkarta. Kota Wonosari terletak di sebelah tenggara kota Yogyakarta (Ibukota Propinsi Daerah Istimewa Yogyakarta), dengan jarak $\pm 39 \mathrm{~km}$. Wilayah Kabupaten Gunungkidul dibagi menjadi 18 Kecamatan dan 144 desa. Batas Wilayah Kabupaten Gunungkidul: Sebelah Barat: Kabupaten Bantul dan Sleman (Propinsi DIY). Sebelah Utara: Kabupaten Klaten dan Sukoharjo (Propinsi Jawa Tengah). Sebelah Timur: Kabupaten Wonogiri (Propinsi Jawa Tengah). Sebelah Selatan: Samudera Hindia.

Kabupaten Gunungkidul terdiri dari 18 kecamatan, 144 desa, 1416 dusun, 1583 RW, dan 6844 RT. Kecamatan yang ada di Gunungkidul antara lain: Kecamatan Panggang, 
Purwosari, Paliyan, Saptosari, Tepus, Tanjungsari, Rongkop, Girisubo, Semanu, Ponjong, KarangMojo, Wonosari, Playen, Patuk, Gedangsari, Nglipar, Ngawen, dan Semin. Dari 144 desa, 141 desa masuk klasifikasi Swadaya dan 3 desa termasuk desa Swasembada

Dengan tingkat pendidikan dan terbatasnya sarana yang dimiliki tentu saja aparat desa belum semuanya mampu menggunakan Teknologi dengan lancar, hal ini tentu akan menjadi hambatan dalam pencapaian kinerja aparat secara keseluruhan. Penggunaan Teknologi wajib bagi desa-desa, karena pelaporan harus dilukukan secara online. Pemanfaatan teknologi tersebut mencakup adanya (a) pengolahan data, pengolahan informasi, sistem manajemen dan proses kerja secara elektronik dan (b) pemanfaatan kemajuan Teknologi agar pelayanan publik dapat diakses secara mudah dan murah oleh masyarakat (Dwi Sapartiningsih \& Kristianto, 2018).

Teknologi berkaitan dengan komputer, perangkat, jaringan seperti internet. Teknologi selain sebagai teknologi komputer diperuntukan dalam pemrosesan dan penyimpanan informasi, berfungsi sebagai media teknologi komunikasi untuk penyebaran informasi. Teknologi untuk meningkatkan kemampuan manusia dan komputer mampu mengerjakan yang tidak dapat dilakukan oleh manusia (Hariyani, 2016).

Aktivitas di desa yang semakin banyak, tidak mungkin untuk dilakukan secara manual, oleh karena itu perlu didukung adanya teknologi dan sekaligus pemanfaatannya agar kinerja dapat maksimal.
Maksimalnya suatu pekerjaan akan terlihat dari keakuratan dan ketepatan hanya dapat dicapai dengan bantuan teknologi (Puspasari \& Purnama, 2018). Pemanfaatan teknologi dapat meningkatkan produktivitas dan mengurangi tingkat kesalahan (Abbas et al., 2014).

Pemanfaatan

Teknologi tersebut mencakup (a) pengolahan data, pengolahan informasi, sistem manajemen dan proses kerja secara elektronik dan (b) pemanfaatan kemajuan Teknologi agar pelayanan public dapat diakses secara mudah dan murah oleh masyarakat. Dari uraian di atas bahwa pemanfaatan Teknologi berupa komputer membantu aparatur desa dalam mengelola dokumen-dokumen desa secara keseluruhan (Dwi Sapartiningsih \& Kristianto, 2018).

Kinerja merupakan aktualisasi antara kemampuan dan motivasi. Kinerja merupakan hasil pencapaian secara nyata dalam periode tertentu baik secara individu maupu n secara kelompok. Kinerja menjadi bukti keberhasilan dan sebagai tolok ukur bagi perusahaan atau lembaga (Tarjo, 2019); (Tarjo, 2020). Kinerja seseorang juga ditentukan oleh kemampuan yang dimilikinya. Kinerja juga dapat ditentukan oleh beberapa faktor sebagai pendukung keberhasilannya (Wahyudi et al., 2018). Kinerja dapat diartikan sebagai prestasi kerja, pelaksanaan kerja, pencapaian kerja, hasil kerja (Jaitun, 2013). Kinerja merupakan hasil kegiatan atau program yang akan atau telah dicapai sehubungan dengan penggunaan anggaran dengan kuantitas dan kualitas yang terukur (Yuliani, 2014).

Berdasarkan hasil analisis dan 
observasi dilapangan bahwa aparat desa dalam pemanfaatan Teknologi seperti komputer agar dapat mempermudah aparatur desa dalam mengelola dokumen-dokumen desa secara umum masih ditemukan kelemahan (Iqlima Azhar, Darwanis, 2013); (Yuliani, 2014); (Anggiriawan at all, 2018) hasil penelitian menyimpulkan bahwa kompetensi yang dimiliki oleh sumberdaya manusia masih tergolong rendah dan perlu ditingkatkan lagi. Pemanfaatan Teknologi di pemerintahan desa, untuk membantu aparatur desa agar dalam melakukan pekerjaan lebih maksimal.

Penelitian ini dilakukan untuk melengkapi hasil temuan penelitan terdahulu yang telah diuraikan diatas. Dengan demikian berdasar pada latar belakang di atas, maka penlulis membuat judul penelitian "Pengaruh Kompetensi Sumber Daya Manusia Dan Pemanfaatan Teknologi Terhadap Kinerja Aparatur Desa (Studi Kasus Kantor Kepala Desa di Wilayah Kabupaten Gunungkidul, Yogyakarta)".

\section{TINJAUAN PUSTAKA}

\section{Kompetensi Sumber Daya Manusia}

Kompetensi merupakan kemampuan seseorang dalam melakukan atau melaksanakan pekerjaannya yang didasari oleh keterampilan, pengetahuan, kreativitas dan pengamalan yang ada dalam dirinya untuk menghasilkan suatu kinerja yang diharapkan

2. Kemampuan

Pemanfaatan Teknologi

Teknologi yaitu suatu teknologi yang mempunyai fungsi dalam mengolah data, memproses data, memperoleh, menyusun, menyimpan, mengubah data dengan berbagai cara untuk mendapatkan informasi yang bermanfaat atau berkualitas

\section{Kinerja}

Sangat penting perusahaan melakukan penilaian kinerja karyawannya karena merupakan penentuan secara periodik efektivitas operasional suatu organisasi terkait dengan sasaran, standar dan kriteria yang telah ditetapkan sebelumnya.

\section{Model Penelitian}

Menurut pendapat Sugiyono (2017) "Model penelitian merupakan sintesa yang mencerminkan keterkaitan antara variabel yang diteliti dan merupakan tuntunan untuk memecahkan masalah penelitian serta merumuskan hipotesis yang berbentuk bagan alur yang dilengkapi penjelasan kualitatif”. Dalam penelitian ini model penelitian yang dibuat sebagai berikut:

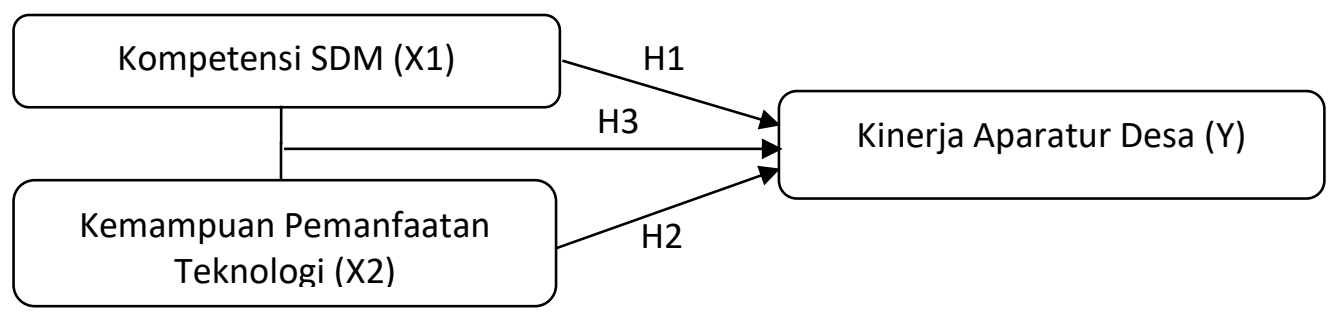

Gambar 1. Paradigma Model Penelitian 


\section{Hipotesis Penelitian}

Hipotesis yang peneliti ajukan adalah sebagai berikut:

$\mathrm{H} 1$ :Diduga terdapat pengaruh yang signifikan antara Kompetensi Sumber Daya Manusia terhadap Kinerja Aparatur Desa Pada Kantor Kepala Desa di Kabupaten Gunungkidul, Yogyakarta.

H2 :Diduga terdapat pengaruh yang signifikan antara Kemampuan Pemanfaatan Teknologi terhadap Kinerja Aparatur Desa Pada Kantor Kepala Desa di Kabupaten Gunungkidul, Yogyakarta.

H3 :Diduga terdapat pengaruh yang signifikan antara Kompetensi Sumber Daya Manusia dan Kemampuan Pemanfaatan Teknologi secara simultan terhadap Kinerja Aparatur Desa Pada Kantor Kepala Desa di Kabupaten Gunungkidul, Yogyakarta.

\section{METODE PENELITIAN}

\section{Populasi}

Populasi merupakan sekumpulan objek yang ditentukan melalui suatu kriteria tertentu yang akan dikategorikan ke dalam objek yang akan diteliti. Menurut Sugiyono (2017) mendefinisikan populasi adalah jumlah wilayah generalisasi yang terdiri atas obyek atau subyek yang mempunyai kualitas dan karakteristik yang ditetapkan oleh peneliti dan kemudian ditarik kesimpulannya. Adapun populasi dalam penelitian berjumlah 144 responden Aparat Kantor Desa di Kabupaten Gunungkidul, Yogyakarta.

\section{Sampel}

Menurut Sugiyono (2017) yaitu "Sampel adalah jumlah dan karakteristik yang dimiliki oleh populasi tersebut". Sedangkan Suharsini Arikunto (2010) berpendapat bahwa "Sampel adalah sebagian atau wakil populasi yang diteliti". Teknik pengambilan sampling dalam penelitian ini adalah samplel jenuh, dimana semua anggota populasi dijadikan sebagai sampel. Dengan demikian sampel dalam penelitian ini berjumlah 144 responden.

\section{Jenis Penelitian}

Jenis penelitian yang dipakai adalah asosiatif, dimana tujuannya adalah untuk mengetahui mencari keterhubungan antara

\section{Metode Analisis Data}

Dalam menganalisis data digunakan uji instrumen, uji asumsi klasik, regresi, koefisien determinasi dan uji hipotesis.

\section{HASIL PENELITIAN}

\section{Uji Intrumen}

Pada pengujian ini
digunakan uji validitas dan uji
reliabilitas. Uji validitas
dimaksudkan untuk mengetahui
ketepatan data tentang kesesuaian
antara yang mau diukur dengan
hasil pengukurannya. Menurut
Sugiyono (2017) "Valid berarti
terdapat kesamaan antara data
yang terkumpul dengan data yang
sesungguhnya". Sedangkan
Ghozali (2013) berpendapat
"Suatu kuesioner dikatakan valid
jika pertanyaan pada kuesioner
mampu untuk mengungkapkan
sesuatu yang akan diukur oleh
kuesioner tersebut". Untuk


melakukan uji validitas dilihat nilai signifikansi 2 tailed dibandingkan dengan 0,05 dengan dengan ketentuan:

1) Jika nilai signifikansi 2 talied < 0,05 , maka instrumen valid,

2) Jika nilai signifikansi 2 talied $>$ 0,05 , maka instrumen tidak valid,

Dari hasil pengujian diperoleh masing-masing item pernyataan pseluruh variabel diperoleh nilai signifikansi 2 tailed sebesar $0,000<0,05$, dengan demikian instrumen valid.

Uji berikutnya adalah uni reliabilitas. Model analisis uji reliabiltas yang digunakan dalam penelitian ini adalah model Alpha Cronbach. Menurut Ghozali
(2013) berpendapat "reliabilitas merupakan alat untuk menguji kekonsistenan jawaban responden atas pertanyaan di kuesioner. Suatu kuesioner dikatakan reliabel jika jawaban seseorang terhadap pertanyaan adalah konsisten atau stabil dari waktu ke waktu". Dalam pengukurannya dilakukan dengan analisis Cronbach's Alpha. Ghozali (2013) mengklasifikasikan nilai Cronbach's Alpha sebagai berikut: 1) Jika nilai Cronbach's Alpha > 0,60, maka dinyatakan reliabel,

2) Jika nilai Cronbach's Alpha < 0,60, maka dinyatakan tidak reliabel,

Adapun hasil pengujiannya sebagai berikut:

Tabel 1. Hasil Pengujian Reliabilitas

\begin{tabular}{|l|c|c|c|}
\hline \multicolumn{1}{|c|}{ Variabel } & Cronbach's Alpha & Standar Kritis Alpha & Keterangan \\
\hline Kompetensi SDM (X1) & 0,734 & 0,600 & Reliabel \\
\hline Kemampuan Pemanfaatan Teknologi (X2) & 0,628 & 0,600 & Reliabel \\
\hline Kinerja Aparatur Desa (Y) & 0,673 & 0,600 & Reliabel \\
\hline
\end{tabular}

Berdasarkan hasil pengujuan di atas, Keseluruhan variabel Kompetensi SDM (X1), Kemampuan Pemanfaatan Teknologi (X2) diperoleh nilai cronbach alpha lebih besar dari 0,60 . Dengan demikian dinyatakan reliabel.

\section{Uji Asumsi Klasik}

Uji asumsi klasik dimaksudkan untuk mengetahui ketepatan sebuah data. Menurut Singgih Santoso (2011) "Sebuah model regresi akan digunakan untuk melakukan peramalan, sebuah model yang baik adalah model dengan kesalahan peramalan yang seminimal mungkin". Karena itu, sebuah model sebelum digunakan seharusnya memenuhi beberapa asumsi, yang biasa disebut asumsi klasik. Dalam penelitian ini uji asumsi klasik yang digunakan adalah meliputi: Uji Normalitas, Uji Multikolinearitas, Uji Autokorelasi, dan Uji Heterokedastisitas. Adapun hasilnya sebagai berikut:

a. Uji Normalitas

Uji normalitas dilakukan untuk menguji apakah dalam model regresi, variabel dependen dan variabel independen berdistribusi normal atau berdistribusi tidak normal. Hasil uji normalitas dengan alat uji Kolmogorov-Smirnov Test, sebagai berikut: 
Tabel 2. Hasil Normalitas Kolmogorov-Smirnov

\begin{tabular}{|c|c|c|c|c|c|c|}
\hline & \multicolumn{3}{|c|}{$\begin{array}{l}\text { Tests of Normality } \\
\text { Kolmogorov-Smirnov }\end{array}$} & \multicolumn{3}{|c|}{ Shapiro-Wilk } \\
\hline & Statistic & $\mathrm{df}$ & Sig. & Statistic & $\mathrm{df}$ & Sig. \\
\hline Kinerja Aparatur Desa $(Y)$ & .074 & 144 & .052 & .989 & 144 & .341 \\
\hline
\end{tabular}

Berdasarkan hasil pengujian pada tabel diatas diperoleh nilai signifikansi 0,052 dimana nilai tersebut lebih besar dari nilai $\alpha=$ 0,050 atau $(0,052>0,050)$. Dengan demikian maka asumsi distribusi persamaan pada uji ini adalah normal.

\section{b. Uji Multikonilieritas}

Pengujian mutlikolinearitas antar variabel bebas tidak memiliki multikolinearitas atau tidak memiliki pengaruh korelasi antara variabel yang ditetapkan sebagai model dalam penelitian. Uji multikolinearitas dilakukan dengan melihat nilai Tolerance Value dan Variance Inflation Factor (VIF). Adapun hasil pengujiannya sebagai berikut: dilakukan untuk meyakini bahwa

Tabel 3. Hasil Uji Multikolinieritas dengan Collinierity Statistic.

\begin{tabular}{|c|c|c|c|c|c|}
\hline \multirow[b]{2}{*}{ Model } & \multicolumn{2}{|c|}{$\begin{array}{l}\text { Coefficients } \\
\text { Unstandardized } \\
\text { Coefficients }\end{array}$} & \multirow{2}{*}{$\begin{array}{l}\text { Standardized } \\
\text { Coefficients } \\
\text { Beta }\end{array}$} & \multicolumn{2}{|c|}{$\begin{array}{c}\text { Collinearity } \\
\text { Statistics }\end{array}$} \\
\hline & $\mathrm{B}$ & Std. Error & & Tolerance & VIF \\
\hline 1 (Constant) & 6.025 & 2.371 & & & \\
\hline Kompetensi SDM (X1) & .391 & .056 & .433 & .779 & 1.284 \\
\hline $\begin{array}{l}\text { Kemampuan Pemanfaatan Teknologi } \\
\text { (X2) }\end{array}$ & .461 & .064 & .450 & .779 & 1.284 \\
\hline
\end{tabular}

Berdasarkan hasil pengujian pada tabel diatas nilai tolerance masing-masing variabel bebas yaitu $0,779<1,0$ dan nilai Variance Inflation Factor (VIF) sebesar $1,284<10$, dengan demikian model regresi ini tidak terjadi multikolinearitas.
Pengujian Autokorelasi digunakan untuk mengetahui ada atau tidaknya penyimpangan korelasi antar anggota sampel. Pengujian dilakukan dengan alat uji Darbin-Watson (DW test). Adapun hasil pengujiannya sebagai berikut:

\section{c. Uji Autokorelasi}

Tabel 4. Hasil Uji Autokorelasi

$$
\text { Model Summary }{ }^{b}
$$

\begin{tabular}{ll|l|l|l|l} 
Model & R & R Square & Adjusted R Square & Std. Error of the Estimate & Durbin-Watson \\
\hline
\end{tabular}

\begin{tabular}{lrrrr}
\hline 1 & $.757^{\mathrm{a}}$ & .573 & .567 & 2.365 \\
\hline a. Predictors: (Constant), Kemampuan Pemanfaatan Teknologi (X2), Kompetensi SDM (X1)
\end{tabular}

b. Dependent Variable: Kinerja Aparatur Desa (Y)

Hasil pengujian pada tabel diatas diperoleh nilai DurbinWatson sebesar 1.724 nilai tersebut berada diantara interval 1.550 - 2.460. Dengan demikian model regresi dinyatakan tidak ada gangguan autokorelasi.

\section{d. Uji Heteroskesdastisitas}

Pengujian

heteroskedastisitas dimaksudkan untuk menguji apakah dalam sebuah model regresi terjadi ketidaksamaan varians residual. Hasil pengujiannya sebagai berikut: 
Tabel 5. Hasil Uji Heteroskesdastisitas dengan Glejser Test Model

\begin{tabular}{|c|c|c|c|c|c|}
\hline \multirow[b]{2}{*}{ Model } & \multicolumn{2}{|c|}{$\begin{array}{l}\text { Unstandardized } \\
\text { Coefficients }\end{array}$} & \multirow{2}{*}{$\begin{array}{c}\text { Standardized } \\
\text { Coefficients } \\
\text { Beta } \\
\end{array}$} & \multirow[b]{2}{*}{$\mathrm{t}$} & \multirow[b]{2}{*}{ Sig. } \\
\hline & $\mathrm{B}$ & Std. Error & & & \\
\hline 1 (Constant) & 2.677 & 1.575 & & 1.699 & .091 \\
\hline Kompetensi SDM (X1) & .027 & .037 & .067 & .710 & .479 \\
\hline $\begin{array}{l}\text { Kemampuan Pemanfaatan } \\
\text { Teknologi (X2) }\end{array}$ & -.051 & .042 & -.113 & $1.196^{-}$ & .234 \\
\hline
\end{tabular}

a. Dependent Variable: RES2

Hasil pengujian dengan menggunakan uji glejser diperoleh nilai Sig. > 0,05. Dengan demikian regression model tidak ada gangguan heteroskesdastisitas.

\section{Analisis Deskriptif}

Pada pengujian ini digunakan untuk mengetahui skor minimum dan maksimum, mean score dan standar deviasi dari masing-masing variabel. Adapun hasilnya sebagai berikut:

Tabel 6. Hasil Analisis Descriptive Statistics

Descriptive Statistics

\begin{tabular}{|l|r|r|r|r|r|} 
& $\mathrm{N}$ & Minimum & Maximum & Mean & Std. Deviation \\
\hline Kompetensi SDM (X1) & 144 & 31 & 46 & 37.74 & 3.986 \\
\hline Kemampuan Pemanfaatan Teknologi (X2) & 144 & 29 & 46 & 38.12 & 3.504 \\
\hline Kinerja Aparatur Desa (Y) & 144 & 29 & 49 & 38.35 & 3.594 \\
\hline Valid N (listwise) & 144 & & & & \\
\hline
\end{tabular}

Kompetensi Sumber Daya Manusia diperoleh varians minimum sebesar 31 dan varians maximum 46 dengan mean score sebesar 37,74 dengan standar deviasi 3,986.

Kemampuan Pemanfaatan Teknologi diperoleh varians minimum sebesar 29 dan varians maximum 46 dengan mean score sebesar 38,12 dengan standar deviasi 3,504.

Kinerja Aparatur Desa diperoleh varians minimum sebesar 29 dan varians maximum 49 dengan mean score sebesar 38,35 dengan standar deviasi

\section{3,594 .}

4. Analisis Verifikatif.

Pada analisis ini dimaksudkan untuk mengetahui pengaruh variabel independen terhadap variabel dependen. Adapun hasil pengujian sebagai berikut:

\section{a. Analisis Regresi Linier Berganda}

Uji regresi ini dimaksudkan untuk mengetahui perubahan variabel dependen jika variabel independen mengalami perubahan. Adapun hasil pengujiannya sebagai berikut:

Tabel 7. Hasil Pengujian Regresi Linier Berganda

\begin{tabular}{|c|c|c|c|c|c|}
\hline \multirow[b]{3}{*}{ Model } & \multicolumn{2}{|c|}{ Coefficients ${ }^{a}$} & \multirow{3}{*}{$\begin{array}{l}\text { Standardized } \\
\text { Coefficients }\end{array}$} & \multirow[b]{3}{*}{$\mathrm{t}$} & \multirow[b]{3}{*}{ Sig. } \\
\hline & \multicolumn{2}{|c|}{$\begin{array}{l}\text { Unstandardized } \\
\text { Coefficients }\end{array}$} & & & \\
\hline & B & Std. Error & & & \\
\hline 1 (Constant) & 6.025 & 2.371 & & 2.541 & .012 \\
\hline Kompetensi SDM (X1) & .391 & .056 & .433 & 6.947 & .000 \\
\hline $\begin{array}{l}\text { Kemampuan Pemanfaatan Teknologi } \\
\text { (X2) }\end{array}$ & .461 & .064 & .450 & 7.216 & .000 \\
\hline
\end{tabular}


Berdasarkan hasil pengujian pada tabel di atas, diperoleh persamaan regresi $\mathrm{Y}$ $=6,025+0,391 \mathrm{X} 1+0,461 \mathrm{X} 2$. Dari persamaan tersebut dijelaskan sebagai berikut:

1) Konstanta sebesar 6,025 diartikan jika Kompetensi Sumber Daya Manusia dan Kemampuan Pemanfaatan Teknologi tidak ada, maka telah terdapat nilai Kinerja Aparatur Desa sebesar 6,025 point.

2) Koefisien regresi Kompetensi Sumber Daya Manusia sebesar 0,391, angka ini positif artinya setiap ada peningkatan Kompetensi Sumber Daya Manusia sebesar 0,391 maka Kinerja Aparatur Desa juga akan mengalami

Tabel 8. Hasil Pengujian Koefisien Korelasi Kompetensi Sumber Daya Manusia Terhadap Kinerja Aparatur Desa.

Correlations $^{\mathrm{b}}$

Kompetensi SDM (X1) Kinerja Aparatur Desa (Y)

\begin{tabular}{llr|r} 
& & & \\
\hline Kompetensi SDM $(X 1)$ & Pearson Correlation & 1 & $.645^{* *}$ \\
\cline { 2 - 4 } & Sig. (2-tailed) & $.645^{* *}$ & .000 \\
\hline \multirow{2}{*}{ Kinerja Aparatur Desa (Y) } & Pearson Correlation & .000 & 1 \\
\cline { 2 - 4 } & Sig. (2-tailed) & & \\
\hline
\end{tabular}

**. Correlation is significant at the 0.01 level (2-tailed).

b. Listwise $\mathrm{N}=144$

Berdasarkan hasil pengujian diperoleh nilai korelasi sebesar 0,645 artinya Kompetensi Sumber Daya

Tabel 9. Hasil Pengujian Koefisien Korelasi Kemampuan Pemanfaatan

Teknologi Terhadap Kinerja Aparatur Desa.

Correlations $^{b}$

Kemampuan Pemanfaatan TI (X2) Kinerja Aparatur Desa (Y)

\begin{tabular}{llrrr}
\hline Kemampuan Pemanfaatan TI (X2) & Pearson Correlation & 1 & $.653^{* *}$ \\
\cline { 2 - 4 } & Sig. (2-tailed) & $.653^{* *}$ & .000 \\
\hline \multirow{2}{*}{ Kinerja Aparatur Desa $(\mathrm{Y})$} & Pearson Correlation & .000 & 1 \\
\cline { 2 - 5 } & Sig. (2-tailed) & & \\
\hline
\end{tabular}

${ }^{\star *}$. Correlation is significant at the 0.01 level (2-tailed)

b. Listwise $\mathrm{N}=144$

$\begin{array}{cclr}\text { Berdasarkan } & \text { hasil } & \text { korelasi sebesar } & 0,653 \text { artinya } \\ \text { pengujian diperoleh } & \text { nilai } & \text { Kemampuan } & \text { Pemanfaatan }\end{array}$


Teknologi memiliki hubungan yang kuat terhadap Kinerja

Aparatur Desa.

Tabel 10. Hasil Pengujian Koefisien Korelasi Kompetensi Sumber Daya

Manusia dan Kemampuan Pemanfaatan Teknologi secara simultan

Terhadap Kinerja Aparatur Desa.

\begin{tabular}{ll|c|r|r} 
Model & $\mathrm{R}$ & $\mathrm{R}$ Square & $\begin{array}{c}\text { Model Summary } \\
\text { Adjusted R Square }\end{array}$ & Std. Error of the Estimate \\
\hline 1 & $.757^{\mathrm{a}}$ & .573 & .567 & 2.365 \\
\hline a. Predictors: (Constant), Kemampuan Pemanfaatan Teknologi (X2), Kompetensi SDM (X1)
\end{tabular}

Berdasarkan hasil pengujian diperoleh nilai korelasi sebesar 0,757 artinya Kompetensi Sumber Daya Manusia dan Kemampuan Pemanfaatan Teknologi secara simultan memiliki hubungan yang kuat terhadap Kinerja Aparatur Desa. c. Analisis Determinasi

Analisis determinasi dimaksudka mengetahui besarnya persentase pengaruh dari variabel independen terhadap variabel dependen baik secara parsial maupun simultan. Adapun hasil pengujian sebagai berikut:

Tabel 11. Hasil Pengujian Koefisien Determinasi Kompetensi Sumber Daya Manusia Terhadap Kinerja Aparatur Desa.

Model Summary

\begin{tabular}{cc|c|c|c|} 
Model & $R$ & R Square & Adjusted R Square & Std. Error of the Estimate \\
\hline
\end{tabular}

\begin{tabular}{lrrrr}
\hline 1 & $.645^{\mathrm{a}}$ & .415 & .411 & 2.758 \\
\hline a. Predictors: (Constant), Kompetensi SDM (X1)
\end{tabular}

Berdasarkan hasil Daya Manusia memiliki pengujian diperoleh nilai kontribusi pengaruh sebesar determinasi sebesar $0,415 \quad 41,5 \%$ terhadap Kinerja artinya Kompetensi Sumber Aparatur Desa.

Tabel 12. Hasil Pengujian Koefisien Determinasi Kemampuan Pemanfaatan Teknologi Terhadap Kinerja Aparatur Desa.

Model Summary

\begin{tabular}{lr|r|r|r} 
Model & $R$ & R Square & Adjusted R Square & Std. Error of the Estimate \\
\hline 1 & $.653^{\mathrm{a}}$ & .427 & .423 & 2.730 \\
\hline a. Predictors: (Constant), Kemampuan Pemanfaatan Teknologi (X2)
\end{tabular}

\begin{tabular}{|c|c|c|c|}
\hline Berda & arkan & hasil & Pemanfaatan \\
\hline ajian & diperoleh & nilai & memiliki kontribusi pengaruh \\
\hline determinasi & sebesar & 0,427 & sebesar $42,7 \%$ terhadap Kinerja \\
\hline artinya & Kema & mpuan & Aparatur Desa. \\
\hline
\end{tabular}

Tabel 13. Hasil Pengujian Koefisien Determinasi Kompetensi Sumber Daya

Manusia dan Kemampuan Pemanfaatan Teknologi Terhadap Kinerja Aparatur Desa.

Model Summary

\begin{tabular}{lr|rrr} 
Model & $\mathrm{R}$ & $\mathrm{R}$ Square & Adjusted R Square & Std. Error of the Estimate \\
\hline 1 & $.757^{\mathrm{a}}$ & .573 & .567 & 2.365 \\
\hline \multicolumn{2}{l}{ a. Predictors: (Constant), Kemampuan Pemanfaatan Teknologi (X2), Kompetensi SDM (X1) }
\end{tabular}


\begin{tabular}{llr}
\multicolumn{2}{c}{ Berdasarkan } & hasil \\
pengujian & diperoleh & nilai \\
determinasi & sebesar & 0,573
\end{tabular} artinya Kompetensi Sumber Daya Manusia dan Kemampuan Pemanfaatan Teknologi secara simultan memiliki kontribusi pengaruh sebesar 57,3\% terhadap Kinerja Aparatur Desa, sedangkan sisanya sebesar $42,7 \%$ dipengaruhi faktor lain.

Tabel 14. Hasil Uji Hipotesis Kompetensi Sumber Daya Manusia Terhadap Kinerja Aparatur Desa.

Coefficients $^{\mathrm{a}}$

\begin{tabular}{|c|c|c|c|c|c|}
\hline \multirow[b]{2}{*}{ Model } & \multicolumn{2}{|c|}{ Unstandardized Coefficients } & \multirow{2}{*}{$\begin{array}{c}\text { Standardized Coefficients } \\
\text { Beta }\end{array}$} & \multirow[b]{2}{*}{$\mathrm{t}$} & \multirow[b]{2}{*}{ Sig. } \\
\hline & B & Std. Error & & & \\
\hline 1 (Constant) & 16.419 & 2.196 & & 7.478 & .000 \\
\hline Kompetensi SDM (X1) & .581 & .058 & .645 & 10.045 & .000 \\
\hline
\end{tabular}

a. Dependent Variable: Kinerja Aparatur Desa $(\mathrm{Y})$

Berdasarkan hasil pengujian pada tabel di atas, diperoleh nilai t hitung $>\mathrm{t}$ tabel atau $(10,045>1,977)$, dengan demikian hipotesis pertama yang diajukan bahwa terdapat

Tabel 15. Hasil Uji Hipotesis Kemampuan Pemanfaatan Teknologi

Terhadap Kinerja Aparatur Desa.

Coefficients $^{a}$

\begin{tabular}{|c|c|c|c|c|c|}
\hline \multirow[b]{2}{*}{ Model } & \multicolumn{2}{|c|}{ Unstandardized Coefficients } & \multirow{2}{*}{$\begin{array}{c}\text { Standardized Coefficients } \\
\text { Beta }\end{array}$} & \multirow[b]{2}{*}{$t$} & \multirow[b]{2}{*}{ Sig. } \\
\hline & $\mathrm{B}$ & Std. Error & & & \\
\hline 1 (Constant) & 12.804 & 2.494 & & 5.133 & .000 \\
\hline Kemampuan Pemanfaatan Teknologi (X2) & .670 & .065 & .653 & 10.285 & .000 \\
\hline
\end{tabular}

Berdasarkan hasil pengujian pada tabel di atas, diperoleh nilai $t$ hitung $>\mathrm{t}$ tabel atau $(10,285>1,977)$, dengan demikian hipotesis kedua yang diajukan bahwa terdapat pengaruh yang signifikan atara Kemampuan Pemanfaatan Teknologi terhadap Kinerja Aparatur Desa diterima.

Uji Hipotesis Simultan (Uji F)

Pengujian hipotesis dengan uji pengaruh yang signifikan atara Kompetensi Sumber Daya Manusia terhadap Kinerja Aparatur Desa diterima.
Pengujian hipotesis dengan uji $\mathrm{t}$ digunakan untuk mengetahui hipotesis parsial mana yang diterima.

Hipotesis pertama: Terdapat pengaruh yang signifikan antara Kompetensi Sumber Daya Manusia terhadap Kinerja Aparatur Desa. 
Tabel 16. Hasil Uji Hipotesis Kompetensi Sumber Daya Manusia dan Kemampuan Pemanfaatan Teknologi Terhadap Kinerja Aparatur Desa.

\begin{tabular}{|c|c|c|c|c|c|c|}
\hline \multirow{2}{*}{\multicolumn{2}{|c|}{ Model }} & \multicolumn{3}{|c|}{ ANOVA $^{a}$} & \multirow[b]{2}{*}{$\mathrm{F}$} & \multirow[b]{2}{*}{ Sig. } \\
\hline & & Sum of Squares & df & Mean Square & & \\
\hline 1 & Regression & 1058.392 & 2 & 529.196 & 94.626 & $.000^{\mathrm{b}}$ \\
\hline & Residual & 788.545 & 141 & 5.593 & & \\
\hline & Total & 1846.937 & 143 & & & \\
\hline
\end{tabular}

Berdasarkan hasil pengujian pada tabel di atas, diperoleh nilai $\mathrm{F}$ hitung $>\mathrm{F}$ tabel atau $(94,626>2,670)$, dengan demikian hipotesis ketiga yang diajukan bahwa terdapat pengaruh yang signifikan atara Kompetensi Sumber Daya Manusia dan Kemampuan Pemanfaatan Teknologi terhadap Kinerja Aparatur Desa diterima.

PEMBAHASAN

HASIL PENELITIAN

1. Pengaruh Kompetensi Sumber Daya Manusia Terhadap Kinerja Aparatur Desa

Dari hasil analisis diperoleh variabel Kompetensi Sumber Daya Manusia berpengaruh signifikan terhadap Kinerja Aparatur Desa dengan nilai korelasi sebesar 0,645 artinya kedua variabel memiliki hubungan yang kuat dengan kontribusi pengaruh sebesar $41,5 \%$. Pengujian hipotesis diperoleh nilai $\mathrm{t}$ hitung $>\mathrm{t}$ tabel atau $(10,045>1,977)$. Dengan demikian hipotesis pertama yang diajukan bahwa terdapat berpengaruh signifikan antara Kompetensi Sumber Daya Manusia terhadap Kinerja Aparatur Desa diterima.
2. Pengaruh Pemanfaatan Terhadap Kinerja Aparatur Desa

Dari hasil analisis diperoleh variabel Kemampuan Pemanfaatan Teknologi berpengaruh signifikan terhadap Kinerja Aparatur Desa dengan nilai korelasi sebesar 0,653 artinya kedua variabel memiliki hubungan yang kuat dengan kontribusi pengaruh sebesar $42,7 \%$. Pengujian hipotesis diperoleh nilai $\mathrm{t}$ hitung $>\mathrm{t}$ tabel atau $(10,285>1,977)$. Dengan demikian hipotesis kedua yang diajukan bahwa terdapat berpengaruh signifikan antara Kemampuan Pemanfaatan Teknologi terhadap Kinerja Aparatur Desa diterima.

3. Pengaruh Kompetensi Sumber Daya Manusia dan Kemampuan Pemanfaatan Teknologi Terhadap Kinerja Aparatur Desa

Dari hasil analisis diperoleh variabel Kompetensi Sumber Daya Manusia dan Kemampuan Pemanfaatan Teknologi berpengaruh signifikan terhadap Kinerja Aparatur Desa dengan diperoleh persamaan regresi $\mathrm{Y}=$ $6,025+0,391 X 1+0,461 X 2$, nilai korelasi sebesar 0,757 artinya kedua variabel memiliki hubungan yang kuat dengan kontribusi pengaruh sebesar $57,3 \%$ 
sedangkan sisanya sebesar $42,7 \%$ dipengaruhi faktor lain. Pengujian hipotesis diperoleh nilai $\mathrm{F}$ hitung $>$ F tabel atau $(94,626>2,670)$. Dengan demikian hipotesis ketiga yang diajukan bahwa terdapat berpengaruh signifikan antara Kompetensi Sumber Daya Manusia dan Kemampuan Pemanfaatan Teknologi terhadap Kinerja Aparatur Desa diterima.

\section{KESIMPULAN DAN SARAN}

\section{A. Kesimpulan}

1. Kompetensi Sumber Daya Manusia berpengaruh signifikan terhadap Kinerja Aparatur Desa nilai korelasi sebesar 0,645 atau kuat dengan kontribusi pengaruh sebesar 41,5\%. Uji hipotesis diperoleh nilai $\mathrm{t}$ hitung $>\mathrm{t}$ tabel atau $(10,045>1,977)$. Dengan demikian terdapat pengaruh yang signifikan antara Kompetensi Sumber Daya Manusia terhadap Kinerja Aparatur Desa Pada Kantor Kepala Desa di Kabupaten Gunungkidul, Yogyakarta.

2. Kemampuan Pemanfaatan Teknologi berpengaruh signifikan terhadap Kinerja Aparatur Desa dengan nilai korelasi sebesar 0,653 atau kuat dengan kontribusi pengaruh sebesar $42,7 \%$. Uji hipotesis diperoleh nilai $\mathrm{t}$ hitung $>\mathrm{t}$ tabel atau $(10,285>1,977)$. Dengan demikian terdapat pengaruh yang signifikan antara Kemampuan Pemanfaatan Teknologi terhadap Kinerja Aparatur Desa Pada Kantor Kepala Desa di Kabupaten Gunungkidul, Yogyakarta.
3. Kompetensi Sumber Daya Manusia dan Kemampuan Pemanfaatan Teknologi berpengaruh signifikan terhadap Kinerja Aparatur Desa dengan nilai korelasi sebesar 0,757 atau kuat dengan kontribusi pengaruh sebesar $57,3 \%$ sedangkan sisanya sebesar $42,7 \%$ dipengaruhi faktor lain. Uji hipotesis diperoleh nilai $\mathrm{F}$ hitung $>\mathrm{F}$ tabel atau $(94,626>2,670)$. Dengan demikian terdapat pengaruh yang signifikan antara Kompetensi Sumber Daya Manusia dan Kemampuan Pemanfaatan Teknologi secara simultan terhadap Kinerja Aparatur Desa Pada Kantor Kepala Desa di Kabupaten Gunungkidul, Yogyakarta.

\section{B. Saran}

1. Lembaga harus memberikan pelatihan-pelatihan agar aparat desa memiliki cukup kemampuan yang diharapkan dalam rangka peningkatan skill yang baik.

2. Lembaga harus menfasilitasi perangkat dalam melakukan pekerjaan pegawainya dengan tekonologi yang diperlukan dan melatih agar mampu mengoperasinalkannya dengan baik.

3. Kinerja lembaga dapat ditingkatkan dengan memberdayakan pegawai dengan membekali pengetahuan yang cukup dan melek dengan tekonologi sehingga pelayanan dapat lebih optimal. 


\section{DAFTAR PUSTAKA}

Abbas, J., Muzaffar, A., Mahmood, H. K., Ramzan, M. A., \& Ul Hassan Rizvi, S. S. (2014). Impact of technology on performance of employees (a case study on Allied Bank Ltd, Pakistan). World Applied Sciences Journal, 29 (2), 271 276.

Akhmad Syarifudin. (2014).

Pengaruh Kompetensi SDM dan Peran Audit Intern terhadap Kualitas Laporan Keuangan Pemerintah Daerah dengan Variabel Intervening Sistem Pengendalian Internal Pemerintah (Studi empiris pada Pemkab Kebumen) Jurnal Fokus Bisnis, Volume 14, No 02, Desember 2014, 14 (25), 26-44.

Anggiriawan, P. B., \& Sanjaya, Komang Adi Kurniawan Saputra, I. K. P. W. (2018). Prinsip Dualitas Dan Akuntansi Sumber Daya Manusia Dalam Keberhasilan Pengelolaan Dana Desa. Jurnal Analisa Akuntansi Dan Perpajakan, 2 (September), 1-14.

Dwi Sapartiningsih, S., \& Kristianto, D. (2018). Analisis Pengaruh Kompetensi Sumber Daya Manusia, Pemanfaatan Teknologi, Partisipasi Penganggaran Dan Pengawasan Terhadap Akuntabilitas Pengelolaan Dana Desa. Jurnal Akuntansi Dan Sistem Teknologi, 14 (1), 100-114.

Hariyani ，D. S. (2016). Analisis Pengaruh Kompetensi Aparatur Pemerintahan Desa Terhadap Penggunaan Teknologi Accounting Information
System Pada Desa-Desa Di Kabupaten Madiun. Jurnal Akuntansi Dan Pendidikan, 5 (2), 89-100.

Hariyani, D. S. (2016). Analisis Pengaruh Kompetensi Aparatur Pemerintahan Desa Terhadap Penggunaan Teknologi Accounting Information System Pada Desa-Desa Di Kabupaten Madiun. Jurnal Akuntansi Dan Pendidikan, 5 (2), 89-100.

Iqlima Azhar, Darwanis, S. A. (2013). Pengaruh Kualitas Aparatur Daerah, Regulasi, Dan Sistem Informasi Terhadap Manajemen Aset (Studi pada SKPD Pemerintah Kota Banda Aceh). Jurnal Akutannsi, 2 (17), 15-26.

Jaitun. (2013). Kinerja Aparatur Desa Dalam Penyelenggaraan Pemerintah Desa Di Desa Sepala Dalung Kecamatan Sesayap Hilir Kabupaten Tana Tidung. EJournal Pemerintahan Integratif, 1 (2), 13-27.

Kaso, N., Mariani, M., Ilham, D., Firman, F., Aswar, N., \& Iksan, M. (2021). The Principal's Leadership: How to Improve the Quality of Teaching and Learning Process in State Junior High School of Luwu. Jurnal Ad'ministrare, 8(1), 49-58. https://doi.org/10.26858/ja.v8i 1.19126

Kaso, N., Nurjihad, A., Ilham, D., \& Aswar, N. (2021). Facebook and its Impact on Students' Learning Achievement at State Islamic High School of Palopo. Jurnal Studi Guru dan Pembelajaran, 4(1), 1-15. 
Marlinawati, M., \& Wardani, D. K. (2018). Pengaruh Kualitas Sumber Daya Manusia, Pemanfaatan Teknologi, Dan Sistem Pengendalian Intern Terhadap Ketepatwaktuan Pelaporan Keuangan Pemerintah Desa. Kajian Bisnis STIE Widya Wiwaha, 26 (2), 131-143.

Muslimat, A., Muhsin, H., Wahid, H. A., Yulistiana, I., Sunarsi, D., Dewi, K., ... \& Ilham, D. (2021). Develop Technology Based Multimedia For Indonesian Teachers. Journal of Contemporary Issues in Business and Government, 27(1), 1871-1882.

Nawawi, H. (2011). Manajemen Sumber Daya Manusia untuk bisnis yang kompetitif (delapan). Gadjah Mada University Press.

Purwanti, Y. (2021). The Influence Of Digital Marketing \& Innovasion On The School Performance. Turkish Journal of Computer and Mathematics Education (TURCOMAT), 12(7), 118-127.

Puspasari, O. R., \& Purnama, D. (2018). Implementasi Sistem Keuangan Desa dan Kualitas Laporan Keuangan Pemerintah Desa di Kabupaten Kuningan. Jurnal Kajian Akuntansi, 2 (2), 145.

Republik Indonesia. (2014). UndangUndang Republik Indonesia Nomor 6 Tahun 2014 tentang Desa Dk, 53 (9), 1689-1699.

Rifuddin, B., Ilham, D., \& K, N. (2020). Academic Services in Islamic Education Management Study Program: The
Actualization of the Basic Values of the State Civil Apparatus at IAIN Palopo. International Journal of Asian Education, 1(2), 81-94. https://doi.org/10.46966/ijae.v $1 i 2.34$

Sasmito, C. (2012). Pengaruh Peningkatan Sdm Aparatur Pemerintah Terhadap Kualitas Pelayanan KTP Di Kecamatan Batu Marmar Kabupaten Pamekasan. Jurnal Reformasi, 2 (2), 37-39.

Tarjo. (2019). Pengaruh Motivasi Kerja dan Kepuasan Kerja terhadap Kinerja Karyawan (Studi pada RSUD H. Hanafie Muara Bungo). Jurnal Aplikasi Manajemen Dan Inovasi Bisnis, 7 (1), 35-50.

Tarjo. (2020). Pengaruh Budaya Lembaga, Motivasi Kerja, Kepuasan Kerja dan Komitmen Lembaga Terhadap Kinerja Karyawan. Jurnal Riset Teknologi Dan Inovasi Pendidikan, 3 (2), 322-330.

Wahyudi, A., Ngumar, S., \& Suryono, B. (2018). FaktorFaktor Yang Mempengaruhi Kinerja Perangkat Desa Pada Pemerintah Desa di Kabupaten Sumbawa. Proceedings, 1 (1), 360-371.

Wardani, D. K., \& Andriyani, I. (2017). Pengaruh Kualitas Sumber Daya Manusia, Pemanfaatan Teknologi, Dan Sistem Pengendalian Intern Terhadap Keandalan Pelaporan Keuangan Pemerintahan Desa Di Kabupaten Klaten. Jurnal Akuntansi, 5 (2), 88-98. 